\title{
Determination of the heat release rate inside operational road tunnels by comparison with CFD calculations
}

\author{
E. Migoya ${ }^{\mathrm{a}, *}$, J. García ${ }^{a}$, A. Crespo ${ }^{a}$, C. Gago ${ }^{\text {b }}$, A. Rubio ${ }^{\text {b }}$ \\ a Laboratorio de Mecánica de Fluidos, Departamento de ingeniería Energética y Fluidomecánica, Escuela Técnica Superior ingenieros Industriales (ETSii), \\ Universidad Politécnica de Madrid (UPM), Closé Gutiérrez Abascal, 2 - 28006 Madrid, Spain \\ 'EUROESTUDIOS, ingeniería de Consulta, C/Castelló, 128 - 28006 Madrid, Spain
}

\section{A R T I C L E I N F O}

Keywords:

Heat release late

Road tunnel fire

Pool fire

Zone model

CFD

Full-scale experiments

\section{Introduction}

Fires inside road tumnels are some of the most complex phenomena that can be studied in combustion science, involving fluid dynamics, turbulence, chemical kinetics, radiation and multiphase flow (Emmons, 1971; Quintiere, 1998; Tieszen, 2001). This complexity increases when the fire is confined. Several deadly accidents (Mont Blanc Mountain, 39 dead; Tauern, 12 dead) and 2001 (Gleinalm, 8 dead; Saint Gotard, 11 dead) brought back to news the security of road tunnels against fire (Leitner, 2001; Vuilleumier et al., 2002). Although the number of tunnel miles are relatively small, and the rate of accidents inside them are lower than in open roads, an accident involving fire in a tunnel is much more dangerous and causes much more alarm.

In order to diminish the damage produced by a tunnel fire, it's necessary to consider the necessary structural, technical and organizational measures. For instance, to control a fire, two of the most important questions are the detection of the fire and the estimation of the critical velocity, which avoids smoke back-layering upstream from the fire source. Several works are dedicated to study smoke and heat detection systems to identify a fire in an early stage (Aralt and Nilsen, 2009). The estimation of the critical ventilation velocity has been addressed in many works (Hu et al., 2008; Roh et al., 2007; Hwang and Edwards, 2005; Kunsch, 2002; Oka and Atkinson, 1995; Wu and Bakar, 2000) and in all cases this ventilation velocity is function of the HRR. In laboratory conditions or in fire road tests, there are several techniques to estimate the power of a fire. However, it is difficult to estimate the HRR inside an operational tunnel. The research works carried out by Ingason's group are particularly relevant. Ingason and Lönnermark, 2005, shows a method that measures the combustion products in the same way used in experimental and real scale tests (Janssens, 1991). At a distance downstream sufficient for adequate mixing, this procedure measures both the flow rate and concentrations of combustion products collected and removed through an exhaust duct. The differences in treatment and equations to be used are mainly due to the extent to which gas analysis is made. As a minimum, the $\mathrm{O}_{2}$ concentration must be measured. However, the accuracy can be improved by adding instrumentation for measuring the concentration of $\mathrm{CO}_{2}, \mathrm{CO}$ and $\mathrm{H}_{2} \mathrm{O}$. In operational tunnels, it is very difficult to install the necessary equipment to collect all the combustion products, or at least a controlled fraction of them, and carry them to the sensors that analyze the total quantity and composition of the gases. Besides, at high temperatures, the sensors used in an industrial installation do not have the required 


\section{Nomenclature}

$t \quad$ burning time $(s)$

$B \quad$ width of the tunnel section ( $m$ )

L distance to the fire focus

$M \quad$ number of HRR values employed in the database

$N$ number of fire positions values employed in the database
U air speed $(\mathrm{m} / \mathrm{s})$

$V \quad$ volume $\left(\mathrm{m}^{3}\right)$

$W \quad$ heat released rate (MW)

$Z$ number of speed values employed in the database

$\Delta H \quad$ heat of combustion (M] $/ \mathrm{kg})$

$\rho \quad$ density $\left(\mathbf{k g} / \mathrm{m}^{3}\right)$ accuracy. Finally, the maintenance of the sensitive equipments is very complicated if they must suffer the dirty air inside a road tunnel. Other procedure that could be used is based on the relationship between the HRR and the high temperatures in the ceiling. The experiments indicate that there is a correspondence between high $H R R$ and high temperatures (Ingason, 2006a). For instance, the highest temperatures $\left(>1300^{\circ} \mathrm{C}\right)$ are obtained with HRRs larger than $20 \mathrm{MW}$ and low ceiling heights $(\sim 4-5 \mathrm{~m})$ in combination with intermediate ventilation rates (Ingason, 2006b). Therefore, Ingason's method could be used for the estimation of HRR for tunnel fires and can be conducted in practical situations, employing any system such as fiber cable that will be explained in this paper. In general, more work is needed to consider simultaneously the geometrical shape and size of the burning source, the tunnel cross section (especially the height) and the ventilation rate, that are thought to be the principal parameters that determine the temperature level at the ceiling (Ingason, 2006a). However, nowadays during a fire inside a tunnel, the average heat release rate (HRR) is usually estimated according to the type of vehicle. PIARC (1999) cites the examples shown in Table 1 . If a video system is avajlable, the operator could know the type of vehicle, estimate the HRR and adapt the ventilations regime. But this is not a good procedure due to its uncertainty, and because it does not take into accounts the instantaneous evolution of the fire.

In laboratory conditions or in fire road tests, modern heat release calorimeters use the oxygen consumption principle to calculate the HRR from a limited number of gas concentration measurements of species as $\mathrm{O}_{2}, \mathrm{CO}$ and $\mathrm{CO}_{2}$ (Parker, 1982). The method is based on the experimental observation that for most common materials the heat released in their combustion is proportional to the amount of oxygen consumed. The constant of proportionality is around $13.1 \mathrm{MJ} / \mathrm{kg}$ of oxygen consumed (Huggett, 1980). Most small-scale measurements of HRR are made using the Cone Calorimeter (ASTM E1354-03), although a large number of measurements have been made in the FM Fire Propagation Apparatus (ASTM E2058-03), and will continue to be made with its closely related successor, the Advanced Flammability Measurements Apparatus (AFM) (Beaulieu et al., 2003). These tests provide transient measurements of the sample's mass loss rate, HRR, and species generations rates/yields $(\mathrm{CO}, \mathrm{CO}$, soot). The main problem

Table 1

Estimated HRR of road vehicles.

\begin{tabular}{lll}
\hline Velicle type & $\begin{array}{l}\text { Typical fire } \\
\text { powers (MW) }\end{array}$ & Remarks \\
\hline Passenger car & $2.5-5$ & $\begin{array}{l}\text { Fire loads used in fire tests in } \\
\text { Finland }\end{array}$ \\
$\begin{array}{l}\text { 2-3 Cars } \\
\text { Van } \\
\text { Bus }\end{array}$ & 8 & \\
Truck load & 15 & $\begin{array}{l}\text { Fire loads used in EUREKA fire } \\
\text { tests } \\
\text { HRR without very combustible } \\
\text { goods }\end{array}$ \\
$\begin{array}{l}\text { Heavy goods vehicle } \\
\text { Petrol tanker }\end{array}$ & 20 & $\begin{array}{l}\text { Tanker carrying } 50 \mathrm{~m}^{3} \text { of } \\
\text { gasoline }\end{array}$ \\
\hline
\end{tabular}

of all these procedures is that they can not be installed in a road tunnel during operational use.

In the next section, the proposed procedure to calculate the HRR will be explained. In section three, the validation procedure and the experiments will be explained, and at last the conclusions of the work will be commented.

\section{Procedure to calculate HRR}

Three different procedures were considered in order to quantify the HRR; to measure the composition of the combustion products, the direct calculation of the HRR using the measurement of temperature and speed inside the fire, and to compare the temperature measurements with a CFD database. In all cases, two of the main problems were the accuracy and reliability of the sensors, and the possibility of installing the systems in operational tunnels. A tumnel is a problematical place for a sensor, due to the dirt and the difficulty of reparation and maintenance. Therefore, the sensors must be simple, in order to work safely and must be capable of supporting the operating conditions. Besides, it is very difficult to install the necessary equipment to collect all the combustion products, or at least a controlled fraction of them, and carry them to the sensors that analyze the total quantity and composition of the gases. Due to the difficulties associated with the sensors and the complexity of implementing the systems necessary to collect the data in the operational tunnels, only the comparison of the measurements of temperatures with a CFD database has been selected in this paper to calculate the HRR.

Nowadays, many CFD programs can simulate the behavior of a fire and its temperatures and combustion products. A possibility of calculating the HRR would be to create with CFD programs a database that depends on the tunnel characteristics and the ventilation speed inside the tunnel. This database could be compared with temperatures measured by the sensors located inside the tunnel and estimate the HRR. The CFD calculation of temperature distribution is affected considerably by the turbulence model, the grid system setting and also the thermal boundary conditions. For a same heat release rate, the calculation results of the temperature evolution and distribution may also be considerably different for the different settings indicated above (Galdo et al., 2008; Jain et al., 2008; Woodburn and Britter, 1996a,b). To make a full database, general purpose codes, like FLUENT or CFX, in which many of these parameters and situations could be included and changed, require much work and time, therefore the simplified model UPMTUNNEL is proposed alternatively (Migoya, 2003). It is a code for the simulation of accidental fires in road tunnels with longitudinal ventilation. UPMTUNNEL allows making quickly analyses for different combinations of variables like HRR, position of the fire, air velocity, etc. Besides, UPMTUNNEL is fairly simple, includes many of the physics of the CFD models and, as it will be shown, gives results in reasonable agreement with measurements made to calculate the HRR, and it is not so sensitive to turbulence modeling or grid setting. On the other hand, it has the important drawback that it cannot simulate back-layering for ventilation velocities lower than critical. 
Sensors must be properly chosen. Anemometers that are sensitive to the orientation of the incident wind (like the Pitot tube) could underestimate the real wind inside the tunnel. Besides, velocity sensors too close to wall, outside the car cross section, could not measure the air velocity profile. Therefore sonic anemometers must be used. On the other hand, thermal sensors must be capable of giving many representative values of the temperature inside the flow: therefore, they have to be placed in many suitable positjons inside the tunnel. This implies that optical fibers have to be used.

\subsection{Sensors}

In this procedure, it is necessary to know, in addition to the geometric and general characteristics of the tunnel, two magnitudes: the velocity of the air inside the tunnel and the gas temperature distribution. In the following, it will be discussed how to measure them.

\subsubsection{Air velocity}

The selected sensor measures the average speed of the air intercepted between the transmitter and the receiver. In the same section, four of them were vertically distributed, horizontally located and perpendicularly oriented to the air. Therefore, the velocity profile of the air inside the tunnel can be measured and a typical velocity could be estimated.

The procedure only needs an average velocity at each cross section. In longitudinal ventilation tunnels, the mass flow should be the same in any section. If the cross section is constant and the density changes can be neglected (as it happens far from the fire focus), the mean velocity will be the same in any position along the tunnel. The measured velocity should not be disturbed by local effects, such as fans, section changes or the focus of the fire. In a tunnel, the velocity must be measured far from places where there are those local effects. Therefore, in an operational tunnel several sections will be needed to measure the velocity, because the selected section must not be disturbed by the fire.

\subsubsection{Temperature}

The procedure needs many measurements of temperatures at different times and positions. In order to obtain multiple temperature measurements in a reliable and cost effective way, optical fibers were chosen. They are capable of measuring the temperatures each 0.5 or $2 \mathrm{~m}$. In relation to the position of the sensors, the procedure must be designed in order to be employed both in operational and in experimental tumnels. Therefore, the fiber could not be located in that part of cross section where there is traffic. It can not either be too close to the walls because the measurements could take place inside the thermal boundary layer and they may not be representative.

\subsection{Calculation of the HRR}

UPMTUNNEL, or another CFD code, must be employed, using the specific tunnel geometry, to obtain the database of temperature increases for some combinations of $H R R$, air velocity and fire position. This CFD database and the air velocity and temperatures measured during the real fire are the inputs to the interpolation algorithm. Therefore, comparing the measurements and the database, the HRR and the fire position can be estimated. Fig. 1 presents the scheme of the selected procedure; the inputs for the database and the algorithm and the output of the procedure will be explained next.

\subsubsection{Database}

The input data necessary to create the database are:

* Heat release rates. Their values should be close to each other so that the accuracy would be sufficient. Besides, the highest calculation HRR should be higher than that of the maximum expected fire scenario. The only part of the HRR that contributes to temperature rise of the gas is the convective part. To determine the total HRR, the radiation heat could be included as a source term in the energy equation or as a fixed fraction of the total heat released, which is the simplest method, (Migoya et al., 2009). That ratio of the total energy lost by radiation to the total heat released by the burning fuel has been found to be roughly independent of the fire size and to depend strongly on the fuel (Zukoski, 1995). This value varies from 0.25 for methane flames to values as large as 0.5 for acetylene flames. The average and usual value that has been employed is 0.35 (Drysdale, 1999; Jain et al., 2008) but it could be changed if there were any information available about a specific kind of fuel.

* Average speeds. As for HRR, the values of the speeds used for the calculations of the database should be close one to another so that the interpolation accuracy would be enough. The database should contain speeds that are two or three times the critical speed for each HRR.

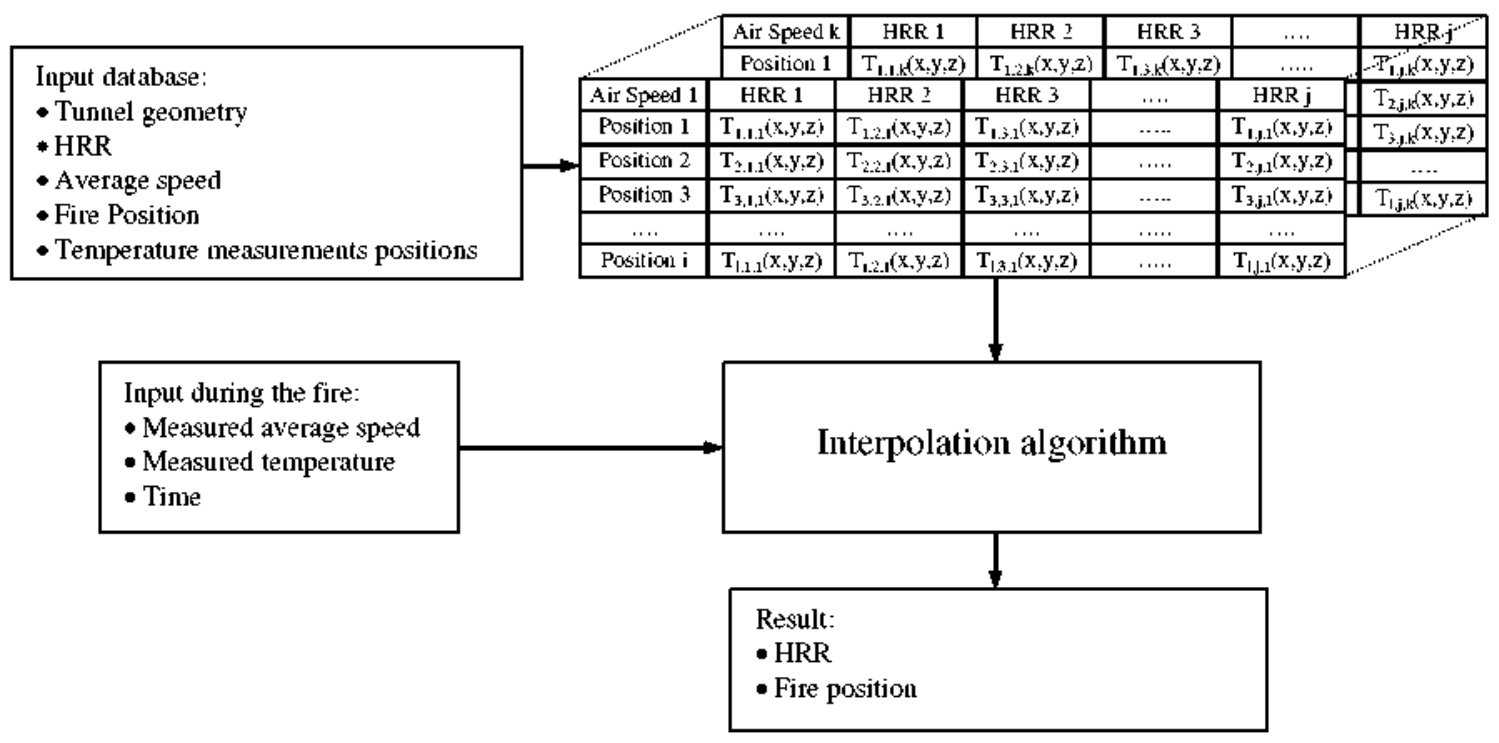

Fig. 1. Scheme of the procedure. 
* Fire positions. The algorithm should use a database created for fires situated in different specific positions along the tunnel. However, in this paper, a single fixed fire position is considered to each experimental case. ln future works a database that includes different fire positions will be considered.

* Fiber cable position. The temperatures of the database are stored in the measurement positions of the cables.

* Geometry, cross section, length, surface roughness, and other characteristics of the tunnel and boundary conditions.

During these particular experiments, the ceiling and the walls were protected by a thermal insulation material. Therefore, al] the tunnel walls are assumed to be adiabatic, so there are not heat loses to walls. Nevertheless, this may not be the general situation, and for each particular case the heat losses to the walls have to be considered. In a real case, this assumption may be reasonable in the first stages of the fire when the highest temperatures are located near the burning object and not very near the walls. When the fire is well developed, it is expected that the heat loses will be significant and the temperatures calculated by UPMTUNNEL for a given HRR will be higher than the real ones; this means that the HRR obtained from the algorithm will be smaller than the actual one. The effect of the underestimation of HRR in the critical velocity to avoid back-layering and breaking the smoke stratification will be treated in later works, including heat loses to the walls.

If temperature increases above ambient are small enough, compressibility effects are small, and the effect on them of ambient temperature may be ignored. On the other hand, for high values of the HRR, when temperature increases are comparable to the absolute value of temperature, this assumption may not be correct, but in that case the variations of ambient temperature will be small compared with temperature variations due to combustion. In both cases the calculated values of the temperature increase above ambient will be independent of the ambient temperature, and this input datum may be ignored for the calculations, having assigned it a fixed value of $15^{\circ} \mathrm{C}$. Nevertheless, the real ambient temperature will be needed to add it to the calculated temperature increase when comparing it with the measurements.

The database has $N \times M \times Z$ files, where $N$ is the number of fire positions analyzed (in this paper 2; one for each cross section), $M$ is the number of HRR values employed and $Z$ the number of speed values studied. As indicated before, the files of the database contain the values of the temperature increase above the ambient temperature. The speed will depend on the air speed in the tunnel entrance, the working conditions of the ventilation fans and pressure differences between entrance and tunnel exit. Therefore, all these effects are taken into account using in the database the correct average air speed inside the tunnel. If the cross section of the tunnel changes, this datum can be substituted by the mass flow rate.

A database that covers all combinations of positions of the fire and the unsteady evolution of the HRR could not be created with our available computer resources. In this work, the database has been created using quasi-steady cases and one fire position for each cross section. At the first stages of the fire, or when the HRR varies very rapidly this quasi-steady assumption obviously will not be valid. The algorithm takes into account the time evolution of the temperature along all the fibers and compares them with those of the database to estimate the values of the HRR at every instant of time. Corrections for unsteady effects, particularly those associated to the early stages of the fire, can be taken into account by considering that the temperature increase at a particular fiber positions is that corresponding to a HRR at a previous instant, with a time delay $L / U$, where $\mathrm{L}$ is the distance to the fire focus, and $\mathrm{U}$ the air speed. In the following, a case of the database will be characterized by a specific combination of air speed and HRR. Obviously, the calculation time, hardware requirements and accuracy for each case are less in zone models that in field models. To study a case using a zone model takes a few minutes, whereas with a general purpose CFD model it takes hours or even days. In this work, 20 ventilation velocities are considered, from $0.2 \mathrm{~m} / \mathrm{s}$ to $4 \mathrm{~m} / \mathrm{s}$, every $0.2 \mathrm{~m} / \mathrm{s}$. Besides, 50 HRRs have been studied, from $1 \mathrm{MW}$ to $50 \mathrm{MW}$, every $1 \mathrm{MW}$. Therefore, the database have 2000 cases that took less than one day to be calculated using the zone model and would take several months employing a general CFD code.

\subsubsection{UMPTUNNEL code}

The model follows a mixed approach, and has characteristics typical of both field and zone models. Like field models, UPMTUNNEL calculates the main properties at every point in the whole domain but, like zone model, the code divides the tunnel in two zones: the plume, located upstream from the point at which the smoke hits the ceiling, and a diffusion zone extending downstream, see Fig. 2 . Each of these two regions is analyzed assuming steady-state conditions. The plume is described by one-dimensional conservation equations for turbulent flows. To deduce the $1 \mathrm{D}$ equations, the 3D problem is considered to be parabolic along the center-line of the flame, and self-similar profiles in planes normal to this line are assumed. The combustion process is described by a conserved scalar approach and infinitely fast reaction, (Servert et al., 1997). The diffusion region is studied as an incompressible unidirectional problem, described by the energy conservation equation. The whole model has been validated, using numerical and experimental results, and employed in several studies (Migoya et al., 2009).

Fig. 3 shows how sensitive is the calculated temperature to HRR when the air speed is higher than critical. The situation corresponds to one of the experimental configurations to be studied later. The temperature is at the center of the tunnel cross section, $0.5 \mathrm{~m}$ below ceiling, where the fiber is supposed to be. The fire position is $390 \mathrm{~m}$ from exit, the ventilation velocity is $5.8 \mathrm{~m} / \mathrm{s}$ and the cross section is approximately rectangular. In this case, temperature increases with HRR at an almost constant rate, and for high values HRR, of the order of $20 \mathrm{MW}$, the dependence of temperature on HRR is still significant. This may be not the case if heat losses to the walls are important.

\subsubsection{Input dato for the algorithm}

Besides the database, the algorithm needs as an input the measured values of the air velocity and the temperature increases dis-
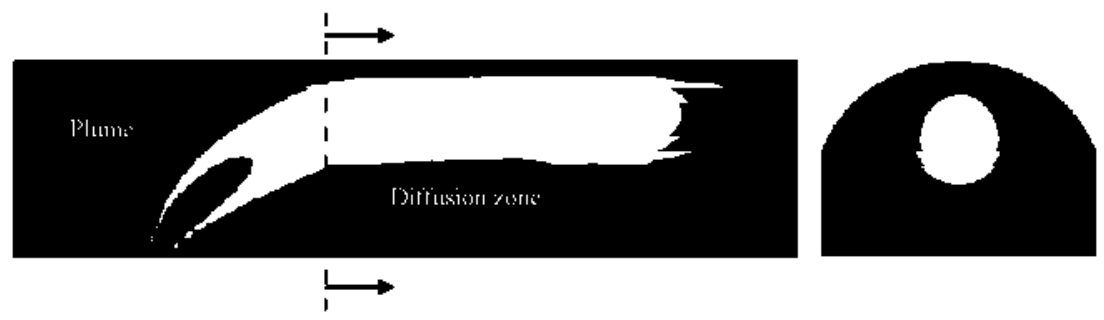

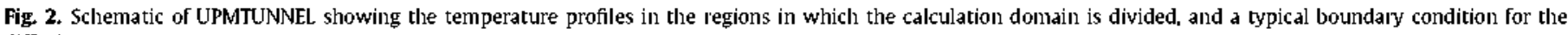
diffusion zone. 


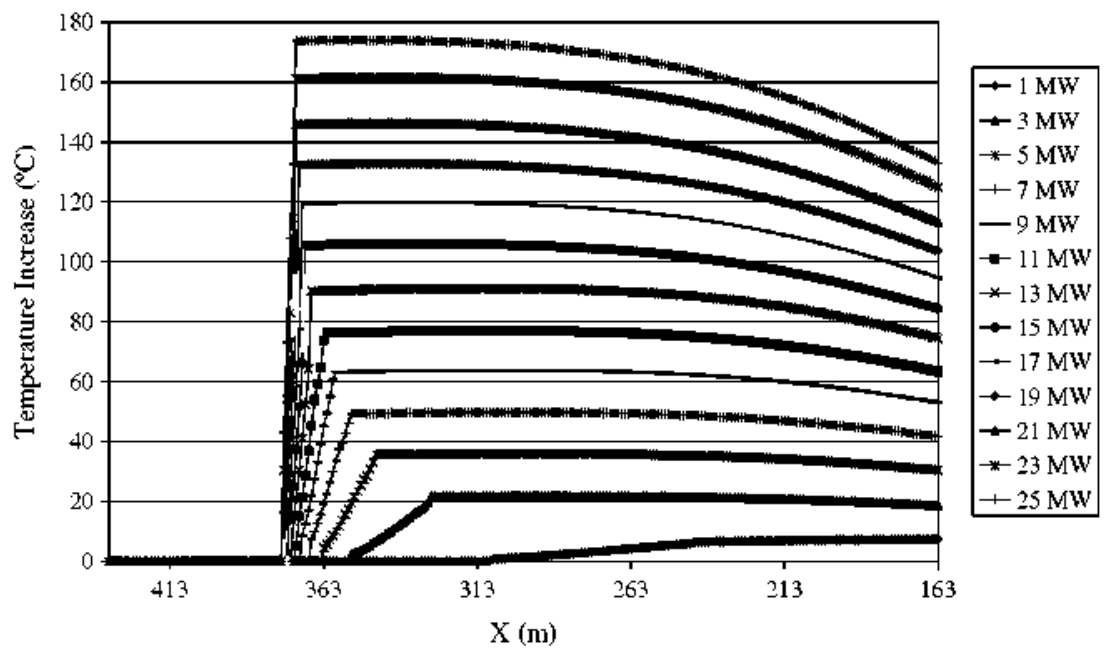

Fig. 3. Example of calculated values of temperature increase distribution along a tumnel for different values of the HHR, calculated with UPMTUNNEL.

tribution along the fibers at each time. The calculation algorithm interpolates among the cases that have values of ventilation velocities and temperature distributions closer to the measured ones in order to calculate the value of HRR at that time.

\subsubsection{Interpolation algorithm}

Obviously, in the database, there will be not exactly the same case that will be recorded by the sensors, and the temperatures in the data set can never be equal to the measured ones. The database must be created using specific combinations of HRR, air speed and fire position. Using the symbols of Fig. 1 and Section 2.2.1, if the fire position is between $i$ and $i+1$ and the measured air speed is between $k$ and $k+1$, multiple linear interpolations will be needed. For instance, the database $T_{i, j, k^{*}}$ for $i$ position, $j$ HRR, and $k$ measured air speed will be created from $T_{i, j, k}$ and $T_{i, j, k+1}$ employing as interpolator parameter the measured air speed; that is the

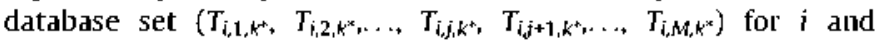
$\left(T_{i+1,1, k^{*}}, T_{i+1,2, k^{*}} \ldots, T_{i+1} j, k^{*}, T_{i+1, j+1}, k^{*}, \ldots, T_{i+1, M, k^{*}}\right)$ for $i+1$. Then, using these new set of estimated data, it will be created the specific database for the measured position, denoted by $i^{*}$. The database $T_{i^{*}, k^{*}}$ will be created from $T_{i, j, k^{*}}$ and $T_{i+1, j k^{*}}$ employing as interpolator parameter the fire position; that is the database set $\left(T_{i, 1, k^{*}}\right.$,

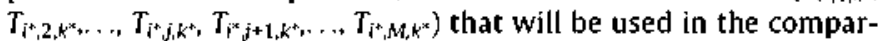
ison with the measured temperatures. At last, a new interpolation between the two nearest HRRs, $j$ and $j+1$, will be made to obtain the final estimated value of HRR that will have to satisfy the condition that the sum of the squares of the differences of the interpolated and measured temperatures is a minimum.

\subsubsection{Output data}

As it has been explained in the previous section, the main result to be obtained by the interpolation algorithm, as indicated in the title of this paper, is the HRR. The computer time needed to calculate each HRR value is less than $2 \mathrm{~s}$. From the measured temperature, the fire position could also be inferred. In fact, this datum is required for the interpolation algorithm. This work does not analyze this output, because, as it will be explained later, the fiber cables near the fire were protected and did not measure useful values during the experiments, and this information is most relevant to determine fire position. Actually, it is expected that the fire position could be obtained using a relationship that links it to the fiber maximum temperature and the air velocity ( $\mathrm{Hu}$ et al., 2006; Kurjoka et al., 2003; Wu and Bakar, 2000), as can be inferred from the Fig. 2. Other possibility is that an operator, using a closed-cir- cuit television system or an automatic fire detection system, could introduce the position of the fire to the interpolation algorithm. In this work, the fire position will be a datum.

\section{Validation and experiments}

The validation procedure has been made in three phases, in order to detect failures. First, the interpolation algorithm, explained in Section 2.2.4, was checked against UPMTUNNEL itself. Then the UPMTUNNEL database was tested using FLUENT results. And at last, the total procedure has been verified using experiments.

\subsection{Validation of the interpolation algorithm by comparison with UPMTUNNEL results}

In order to distinguish between the exactitude of the interpolation algorithm and the database, the first validation step was to compare the results of cases solved directly with UPMTUNNEL with data obtained by interpolation in the UPMTUNNEL database using different combinations of speed and HRR. When the calculation speed is equal to that of the same case of the database, the error is null. When it is necessary to interpolate in speed, the error is between $0.2 \%$ and $0.5 \%$. Therefore, the algorithm works well when taken from a correct database. Table 2 shows same example cases.

\subsection{Database UPMTUNNEL validation using FLUENT resuits}

It is usually assumed that results of field models like FLUENT are more accurate than zone or hybrid models. This is not necessarily true, and the accuracy of the CFD codes in this type of application should be rigorously checked. Nevertheless, there are situations in which simple codes like UPMTUNNEL cannot be applied, like when there is back-layering or the tunnel shape is very complex, and the only alternative is using 3D field models. In any case it has been thought that it will be of interest to compare the results of a fire simulation with FLUENT with those carried out

Table 2

Results for validation of the interpolation algorithm using UPMTUNNEL.

\begin{tabular}{lllc}
\hline Velocity (m/s) & Real HRR (MW) & Estimated (MW) & Error (\%) \\
\hline 2.40 & 10.00 & 10.00 & 0.00 \\
2.40 & 10.50 & 10.50 & 0.00 \\
2.50 & 10.50 & 10.52 & 0.19 \\
2.35 & 21.50 & 21.38 & -0.56 \\
\hline
\end{tabular}




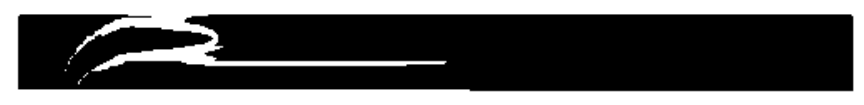

(b) FLUENT
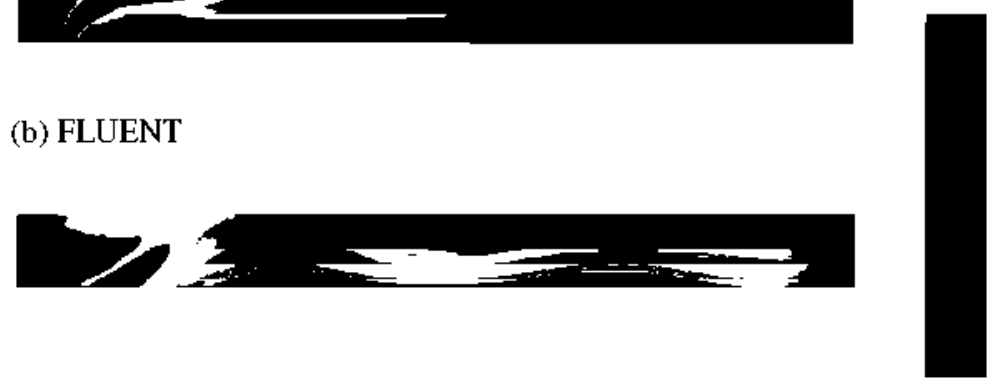

Fig. 4. Example of temperature $\left({ }^{\circ} \mathrm{C}\right)$ contours in the symmetrical longitudinal plane.

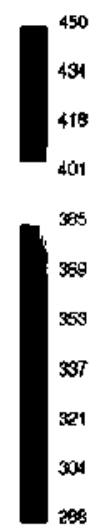

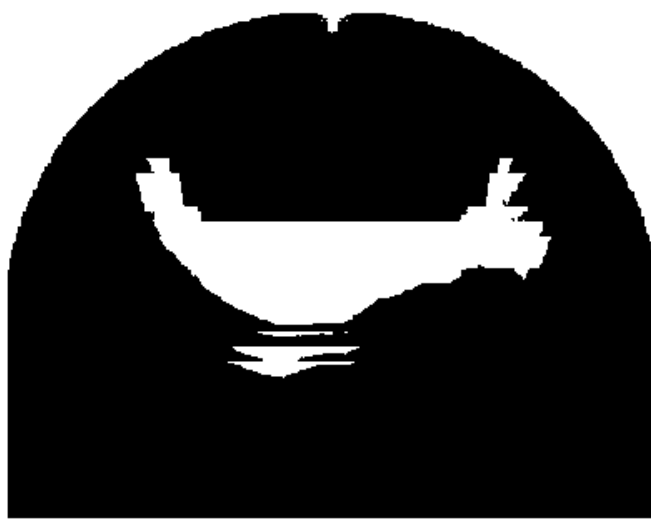

UPMTUNNEL

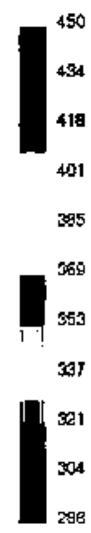

401

395

569

37

321
304
298

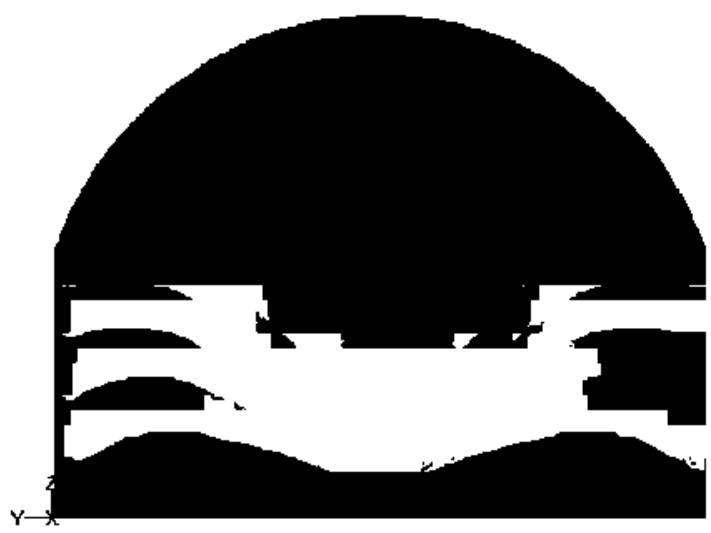

FLUENT

Fig. 5. Example of temperature $\left({ }^{\circ} \mathrm{C}\right)$ contours in the cross section located at $50 \mathrm{~m}$ downstream from the fire.

with UPMTUNNEL and particularly to check the validity of the interpolation method using the temperature distribution obtained with FLUENT for particular values of the HRR. Figs. 4 and 5 show comparisons between both models. There are qualitative differences that can be observed in both figures, particularly near the fire; however, far from the fire where most of the cable sensors are located, the temperatures are not so different. As a matter of fact, as can be observed in Table 3 , in two cases, corresponding to high ventilation velocities, the HRR used in FLUENT is quite close to the one predicted from the database generated with UPMTUNNEL, whereas for lower ventilation velocities discrepancies are more significant. As it was discussed in Migoya et al. (2009), for low ventilation velocities UPMTUNNEL will not be able to reproduce back-layering as observed in Fig. 4.

As indicated previously, other option will be to create a database with FLUENT results, but that will be much more laborious, and besides, it is not guaranteed that the prediction of the HRR of a real fire will be better. This will be substantiated in the next sections, particularly in Table 4 , where it can be seen that the value of the HRR of a real fire is quite well predicted with the database generated with UPMTUNNEL. Besides, the comparison of the results of the different simulation models is not a specific objective of this work, although it is a very important matter to discuss and will be reserved for future work.

\subsection{Validation using experiments}

\subsubsection{Characteristics of the tunnel}

The experiments have been made by TST (TUNNEL SAFETY TESTING, S.A), a Spanish company that operates the facilities of the tunnel test experimental center of "San Pedro de Anes", in the municipality of Siero, in the northern Spanish region of Asturias. The tunnel is $600 \mathrm{~m}$ long with dimensions equivalent to a two lane road tunnel. It has also a removable flat ceiling for reproducing different cross sections. 14 jet fans of $45 \mathrm{KW}$ generate the longitudinal ventilation. Fig. 6 shows the test tunnel layout. The tumel is not straight but the minimum radius of curvature of the middle line is $400 \mathrm{~m}$. During experiments, there were two different cross sections in the tunnel: with flat and vault ceiling, see Fig. 7. The flat ceiling begins at a 150 meter point, whose origin is the south entrance. Four fires, cases 1-4, were below the flat ceiling, and two, cases 5 and 6 , below vault ceiling, see Table 4 .

3.3.1.1. Fire below flat ceiling. The fans push the air from North to south entrances. The fire position was $390 \mathrm{~m}$ from south entrance and the fiber cable covered 272 ms, between 162 and 434 meter point, see Fig. 7. Therefore, all fiber cables were below flat ceiling. Previous computational results show damage risk to the fiber cable near the fire source, so the cables were protected between 362 and

Table 3

Comparison between FLUENT cases and algorithm using UPMTUNNEL database.

\begin{tabular}{lllllr}
\hline Case & Ceiling & $\begin{array}{l}\text { Velocity } \\
(\mathrm{m} / \mathrm{s})\end{array}$ & $\begin{array}{l}\text { FLUENT } \\
\text { HRR }(\mathrm{MW})\end{array}$ & $\begin{array}{l}\text { Calculated } \\
\text { HRR }(\mathrm{MW})\end{array}$ & Error (\%) \\
\hline A & Flat & 2 & 15.38 & 12.87 & -16.32 \\
B & Flat & 2.63 & 15.38 & 15.22 & -1.04 \\
C & Vault & 2 & 15.38 & 13.33 & -13.33 \\
D & Vault & 2.63 & 15.38 & 16.04 & 4.29 \\
\hline
\end{tabular}


Table 4

Descriptions and results of experiments. Cases are represented in Fig. 7 and explained in Section 3.3.1.

\begin{tabular}{|c|c|c|c|c|c|c|c|c|}
\hline Case & Ceiling & Fuel & Number of trays & Volume per tray (I) & Total volume (1) & Real average HRR (MW) & Calculated average HRR (MW) & Error $(\%)$ \\
\hline 1 & Flat & Gasoil & 1 & 150 & 150 & 1.33 & 1.36 & 1.6 \\
\hline 2 & Flat & Gasoil & 2 & 200 & 400 & 2.67 & 2.52 & -5.7 \\
\hline 3 & Flat & Gasoil & 3 & 200 & 600 & 4.00 & 4.64 & 15.9 \\
\hline 4 & Flat & Gasoil & 4 & 150 & 600 & 5.34 & 5.54 & 3.9 \\
\hline 5 & Vault & Heptane & 1 & 300 & 300 & 4.99 & 4.98 & -0.2 \\
\hline 6 & Vault & Heptane & 2 & 300 & 600 & 11.08 & 9.63 & -13.1 \\
\hline
\end{tabular}

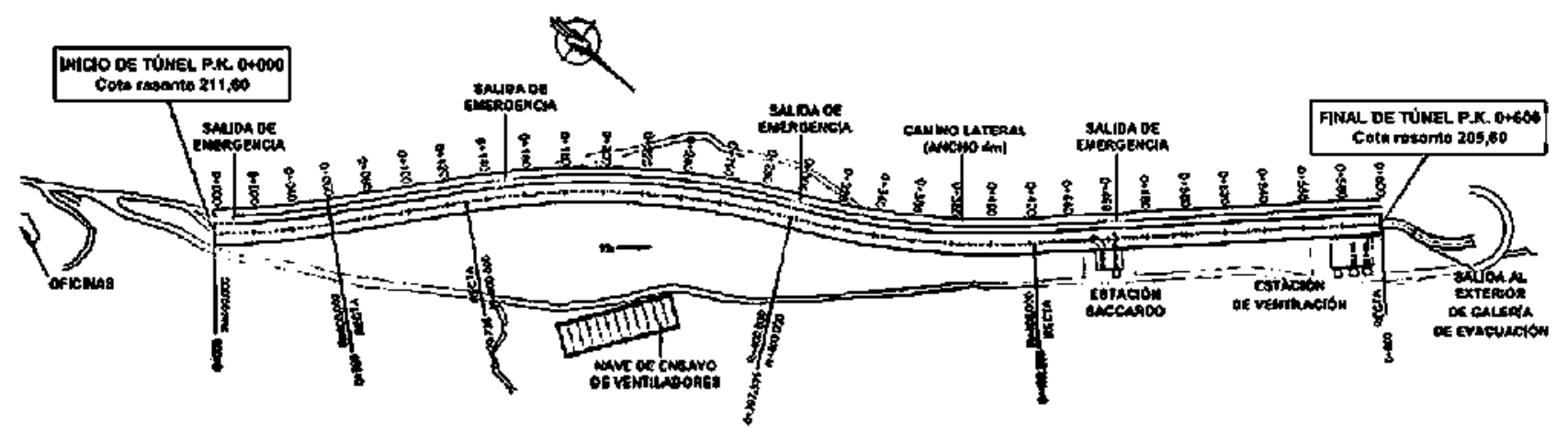

Fig. 6. Test tunnel layout.

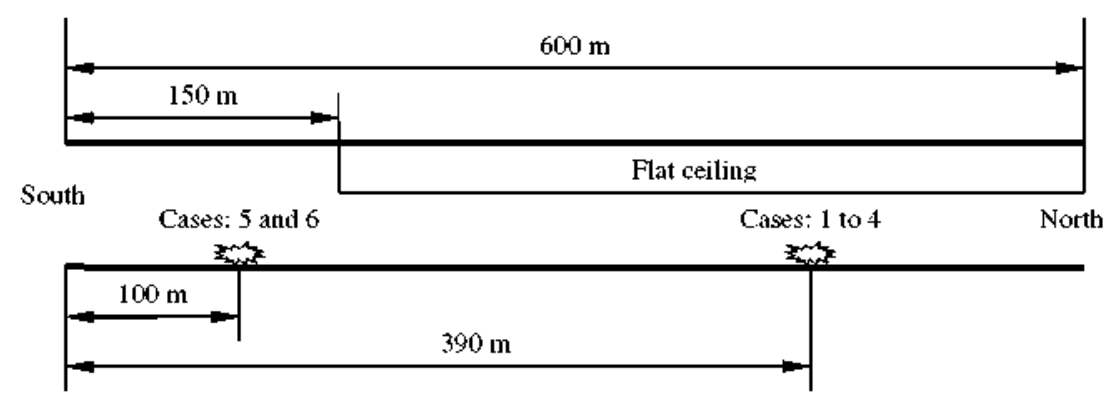

Fig. 7. Tunnel scheme and fire experimental positions.

407 meter point. Then, the interpolation algorithm could not use data $17 \mathrm{~m}$ upstream and $28 \mathrm{~m}$ downstream of the fire.

The average heat released rates were calculated by the equation:

$W=V \rho \Delta H / t$

where $V, \rho, \Delta H$ and $t$ are the volume, the density, the heat of combustion and the burning time of fuel, respectively. The fires below flat ceiling use gasoil with $\rho=860 \mathrm{~kg} / \mathrm{m}^{3}$ and $\Delta H=40.96 \mathrm{MJ} / \mathrm{kg}$. During these experiments erratic behaviours of the gasoil trays could be observed. Therefore, in following experiments, heptane was used.

3.3.1.2. Fire below voult ceiling. In these cases, the fans push the air from south to north. The fire position was $100 \mathrm{~m}$ from south entrance and the fiber cable covered $263 \mathrm{~ms}$, between 4 and 267 meter point. Therefore, part of the fiber cable was below vault ceiling and other below flat ceiling, see Fig. 7 .

The average heat released rates were calculated as in the previous case. The fires below vault ceiling use heptane with $\rho=680 \mathrm{~kg} /$ $\mathrm{m}^{3}$ and $\Delta H=44.6 \mathrm{MJ} / \mathrm{kg}$. The behaviours of the flames were more stable and uniform during the tests.
3.3.1.3. Fiber cable. The temperature was measured every $2 \mathrm{~m}$ using optical fiber. The cables resist $300^{\circ} \mathrm{C}$ with a precision between $0.01{ }^{\circ} \mathrm{C}$ and $0.5^{\circ} \mathrm{C}$. Fig. 8 shows the fiber position in each cross section; see Fig. 8a for the cases 1-4 and Fig. 8b for the cases 5 and 6. In both sections, there are four cables. Three cables are on the ceiling, called $c 1, c 2$ and $c 3$, and one on the vertical wall, named $c 4$. The cables on the ceiling are distributed along the section, one in the center, $c 1$, and the other two to each side, named $c 2$ and $c 3$, at $0.166 \times B$ and $0.333 \times B$ from the center, respectively, where $B$ is the width of the tunnel section. The cable on the vertical wall is at $3.3 \mathrm{~m}$ height. As it has been explained previously, the cable must be outside of the traffic cross section but not too close to the walls to avoid the thermal layer. In the flat ceiling case, the cable must be just below the ceiling but, in the vault ceiling case, the cables hang from rods in order to take more representative temperatures. In al] cases, the cables are just outside of the traffic cross section.

3.3.1.4. Speed sensors. The sonic anemometers measure the average velocity in the line between a transmitter and a receiver. The measurement is based in the disturbance of the wind on transit times of acoustic pulses transmitted in opposite directions. The velocity range is from $-20 \mathrm{~m} / \mathrm{s}$ to $+20 \mathrm{~m} / \mathrm{s}$ with a precision $\pm 0.1 \mathrm{~m} / \mathrm{s}$. Four anemometers were used to measure the average speed at different 


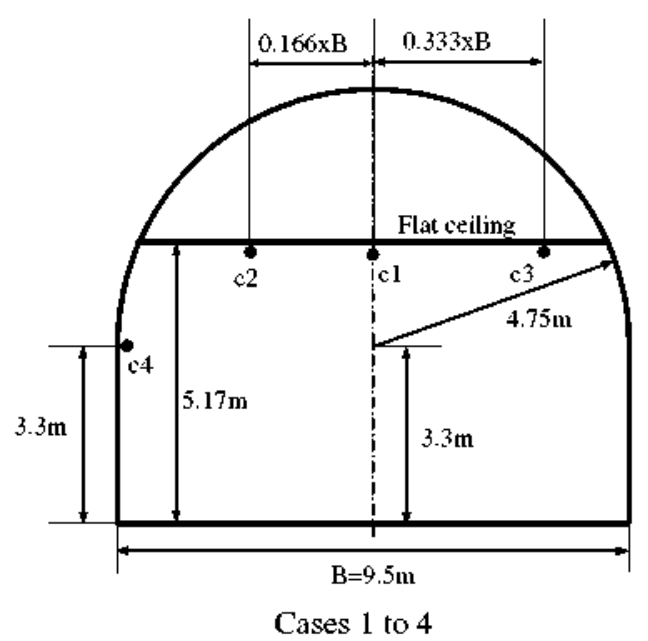

Cases 1 to 4

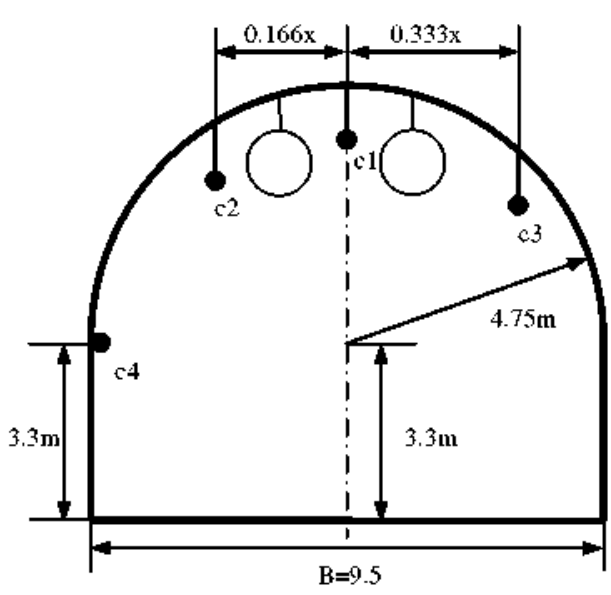

Cases 5 and 6

Fig. 8. Cross section and fiber cable position.

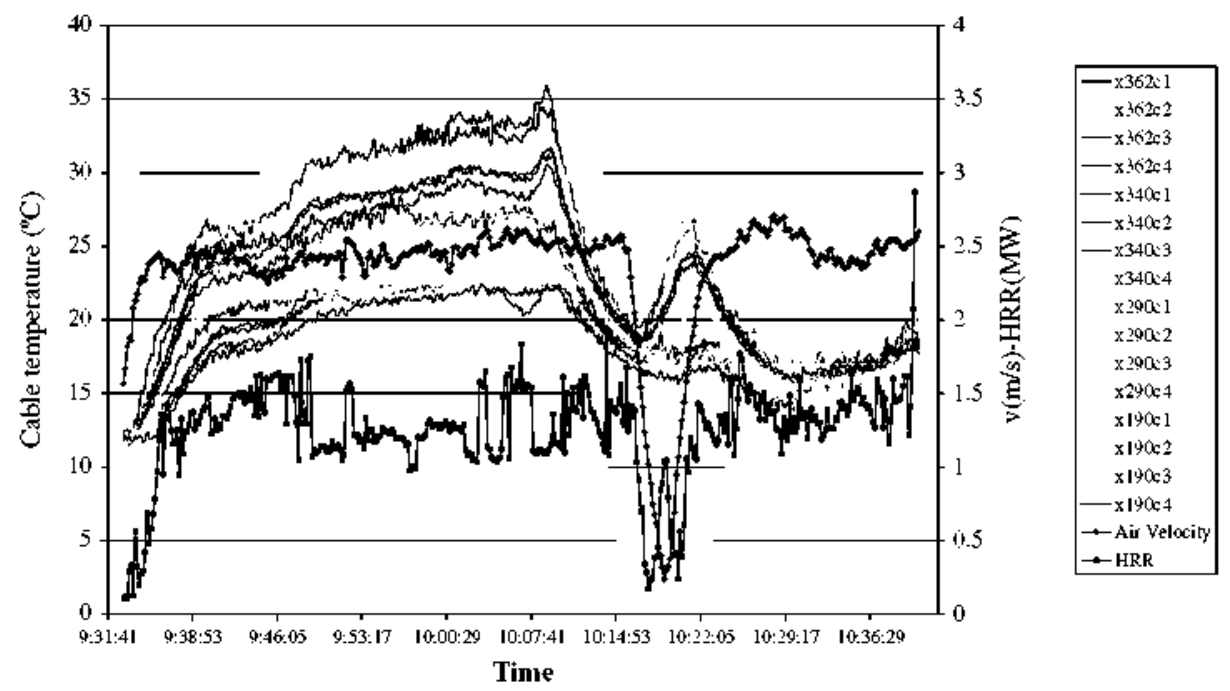

Fig. 9. Fiber cable temperatures and velocity measured and HRR estimated in case 1.

vertical positions. The average position of the anemometers is $480 \mathrm{~m}$ from south entrance. The transmitters and the receivers are $4.75 \mathrm{~m}$ upstream and downstream, respectively of that point, because the line that joins transmitter and receiver must form an angle of $45^{\circ}$ with the middle of the tunnel. Therefore, the transmitter and receiver are separated $9.5 \mathrm{~m}$ in the longitudinal tunne] direction. They were located in opposite walls of the tunnel to measure representative speeds in the cross section at four heights; $1,2.1,3.1$ and $4.2 \mathrm{~m}$, respectively. The input air speed needed by UPMTUNNEL is an average speed inside the tunnel; therefore, the velocity used is the average of the four speeds measured by the four anemometers vertically distributed.

\subsubsection{Results}

3.3.2.1. Flat ceiling. Figs. 9 and 10 , corresponding, respectively to cases 1 and 3 of Table 4, show the evolution of the estimated value of the HRR. In these figures, the evolutions of the measured fiber cable temperature, at several selected positions, and of the measured average velocity are also shown. They illustrate the erratic evolution of the temperature and velocity measured and of the estimated values of HRR at the flat ceiling section using gasoil. Anomalous behaviours of the trays are marked in Fig. 10. Four sec- tions have been selected to show the temperature. The temperature name is $X A A A C B$, where $A A A$ is the measurement meter point; $190 \mathrm{~m}, 290 \mathrm{~m}, 340 \mathrm{~m}$ and $362 \mathrm{~m}$, and $B$ is the cable number; 1-4 increasing as the distance to the middle of the tunnel, see Fig. 8a. In both Figs. 9 and 10, it can be observed that the HRR estimated is more sensitive to changes in the speed measured than to measured temperature variations. In Table 4 , the average values of HRR over the whole burning period are shown. For the four cases, with the flat ceiling cross section, the average value of HRR experimentally obtained from fuel consumption were $1.33,2.67,4$ and $5.34 \mathrm{MW}$, whereas the average values estimated from the database were $1.36,2.52,4.64$ and $5.54 \mathrm{MW}$, respectively. Therefore, the errors for cases $1-4$ were $2 \%,-5 \%, 16 \%$ and $4 \%$, respectively.

Figs. 11 and 12 show representative examples of measured values of temperature along the four fiber cables for cases 1 and 3 of Table 4 , respectively. During experiments in the flat ceiling sections, the fiber cables were protected above the fire. The fire was located in the $390 \mathrm{~m}$ position and there were not measurements between positions corresponding to the 407 and $362 \mathrm{~ms}$. For that reason, in both figures there are gaps between both points. The air direction was from high to low meter reference. Also, the interpolated values of UPMTUNNEL obtained from the databases are 


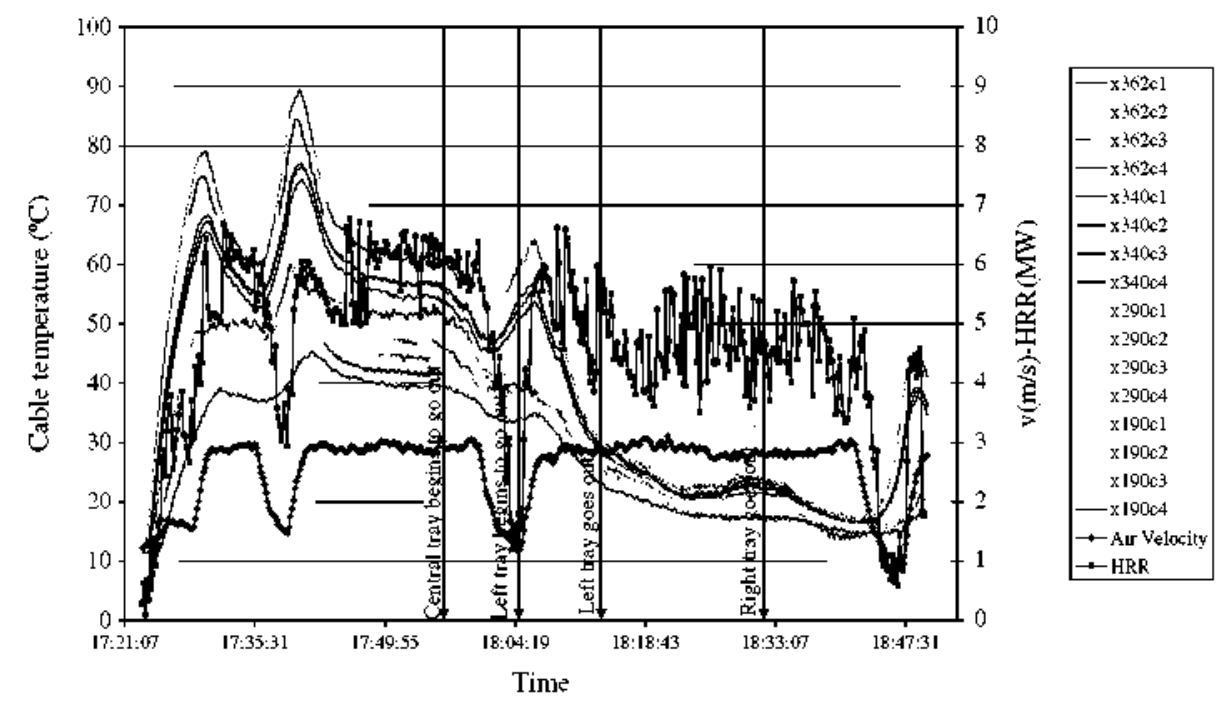

Fig. 10. Fiber cable temperatures and velocity measured and HRR estimated in case 3.

plotted in these figures. The value of the HRR for the particular example of case 1 that appears in Fig. 11, is $1.30 \mathrm{MW}$, and the air speed is $2.49 \mathrm{~m} / \mathrm{s}$, corresponding to instant 10:01:05 of the fire, see Fig. 9. For the particular example of case 3 appearing in Fig. 12, the values of the HRR and air velocity are $5.40 \mathrm{MW}$ and $2.84 \mathrm{~m} / \mathrm{s}$, respectively, and corresponds to instant 17:47:23 of the fire, see Fig. 10. Local estimated values have discrepancies with the experiments, especially in the slope of the curves, but the mean values are next to measurements except for the cable $c 4$ located on the vertical wall. This discrepancy could be resolved modifying some parameters of the UPMTUNNEL model but they have not been changed to use the same parameters in vault and flat ceiling experiments.

3.3.2.2. Vauit ceiling. Figs. 13 and 14 show representative examples of measured temperature along the four fiber cables for cases 5 and 6 of Table 4, respectively. Both figures show a much more uniform and regular evolutions of temperature and the estimated value of HRR, than those shown in Figs. 9 and 10 for flat ceiling; probably, the reason is that in this case heptane instead of gasoil was used. As in the previous section, four sections have been selected to show the temperature. The temperature name is $X A A A C B$, where $A A A$ is the measurement meter point; $110 \mathrm{~m}, 190 \mathrm{~m}, 228 \mathrm{~m}$ y $266 \mathrm{~m}$, and $B$ is the cable number; $1-4$ increasing as the distance to the middle of the tunnel, see Fig. 8b. For cases 5 and 6 , which had a more stable fire, there were not significant velocity variations, therefore it could not be checked whether the estimated value of HRR is more sensitive to changes in the speed measured than to the temperature variations. In fact, the variations of the HRR are very similar to changes of cable temperatures. Table $\mathbf{4}$ shows the average values of HRR. For the two cases, at this cross section, the measured average value of HRR were 4.99 and $11.08 \mathrm{MW}$, whereas the estimated ones were 4.98 and $9.63 \mathrm{MW}$, respectively. Therefore, the errors for cases 5 and 6 were $-0.2 \%$ and $-13 \%$, respectively.

In the vault ceiling sections, the fiber cables did not need any special protection but there were a cross section change. The fire was located in the $100 \mathrm{~m}$ position and there were not valid measurements between the 156 and $161 \mathrm{~ms}$ due to the cross section change. In these cases, the air was from low to high meter reference. Figs. 15 and 16 show the experimental values of temperature distribution along the four fiber cable, which are compared with

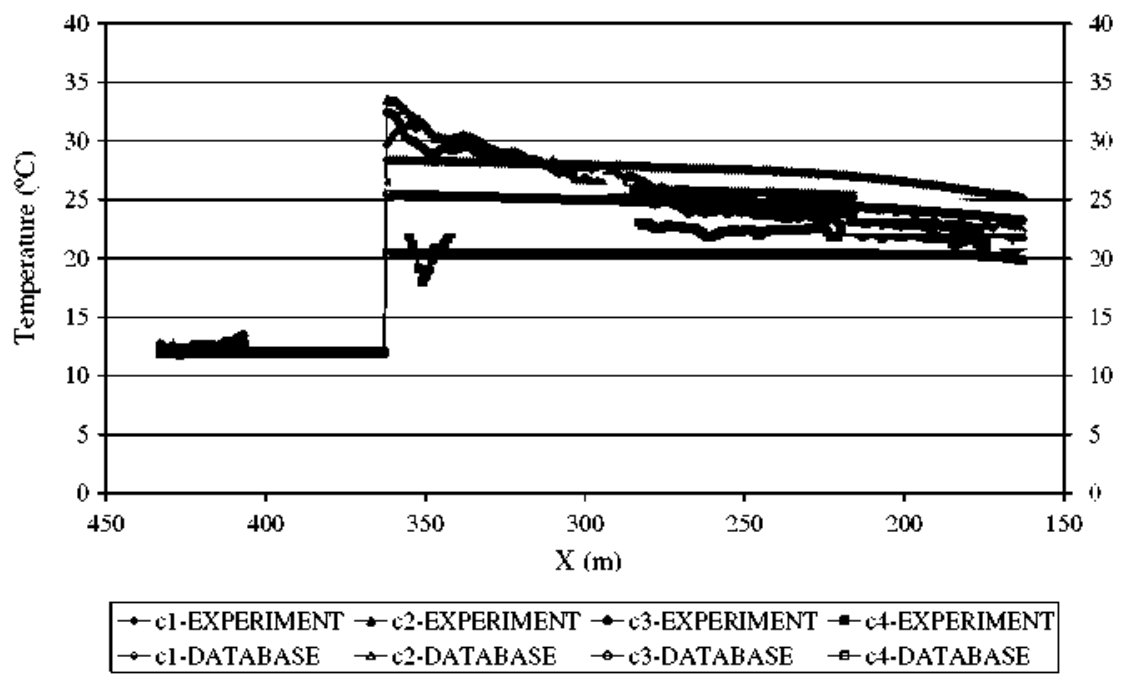

Fig. 11. Temperature distribution along the fiber cables. Comparison of experiments and results of the database. case 1, instant 10:01:05. 


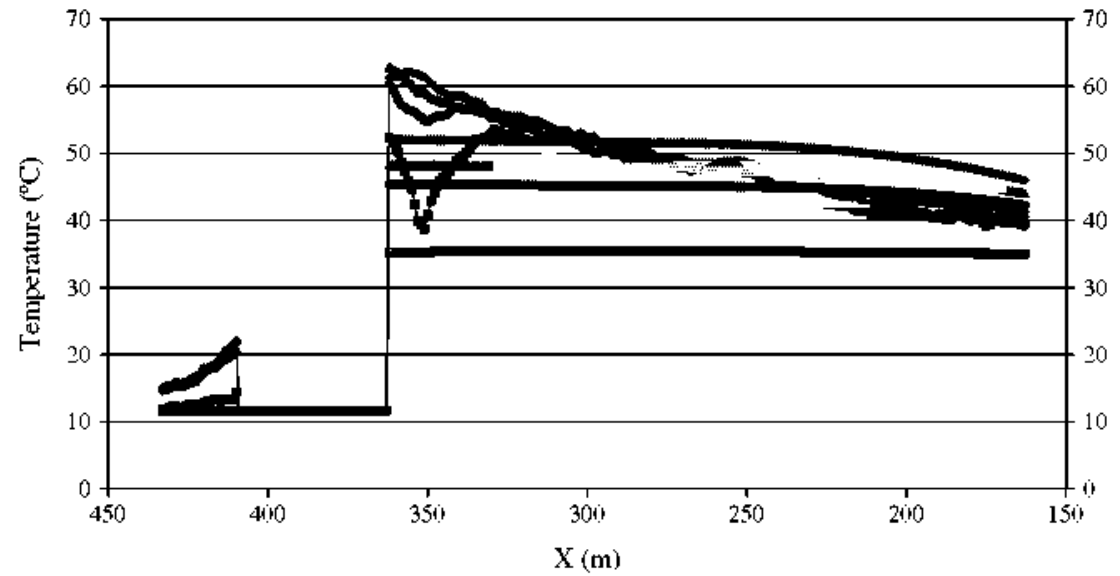

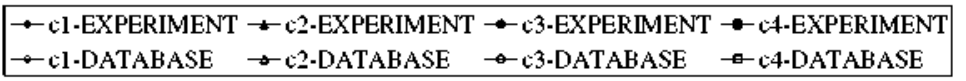

Fig. 12. Temperature distribution along the fiber cables. Comparison of experiments and results of the database. Case 3. instant 17:47:23.

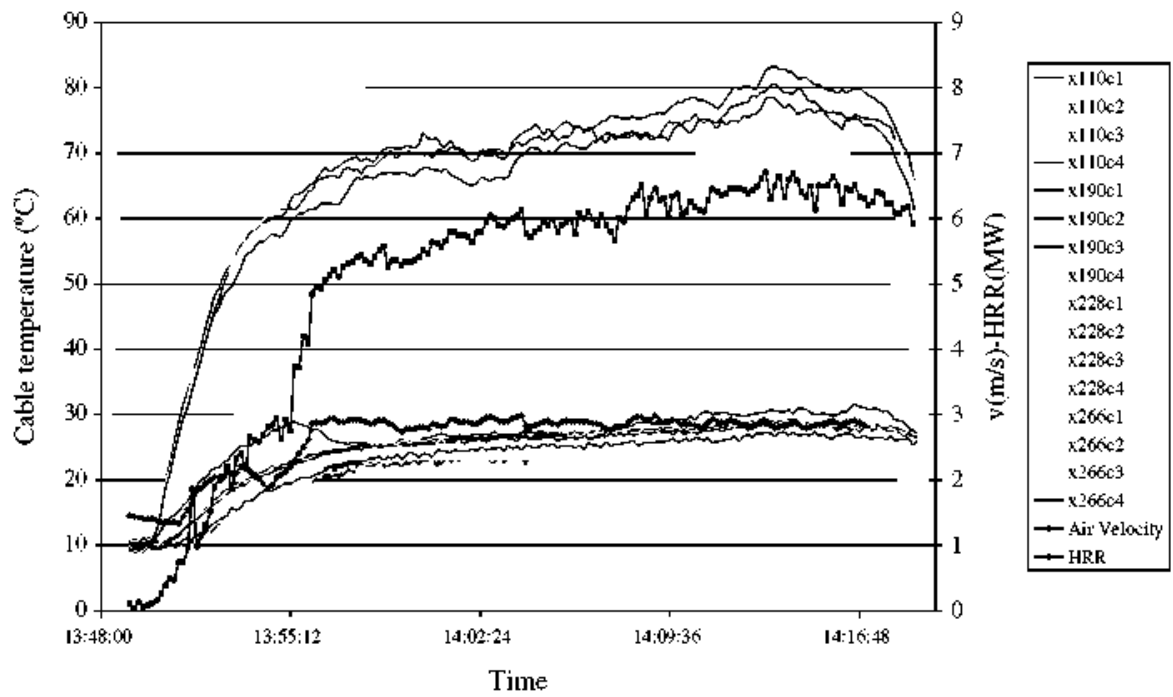

Fig. 13. Fiber cable temperatures and velocity measured and HRR estimated in case 5.

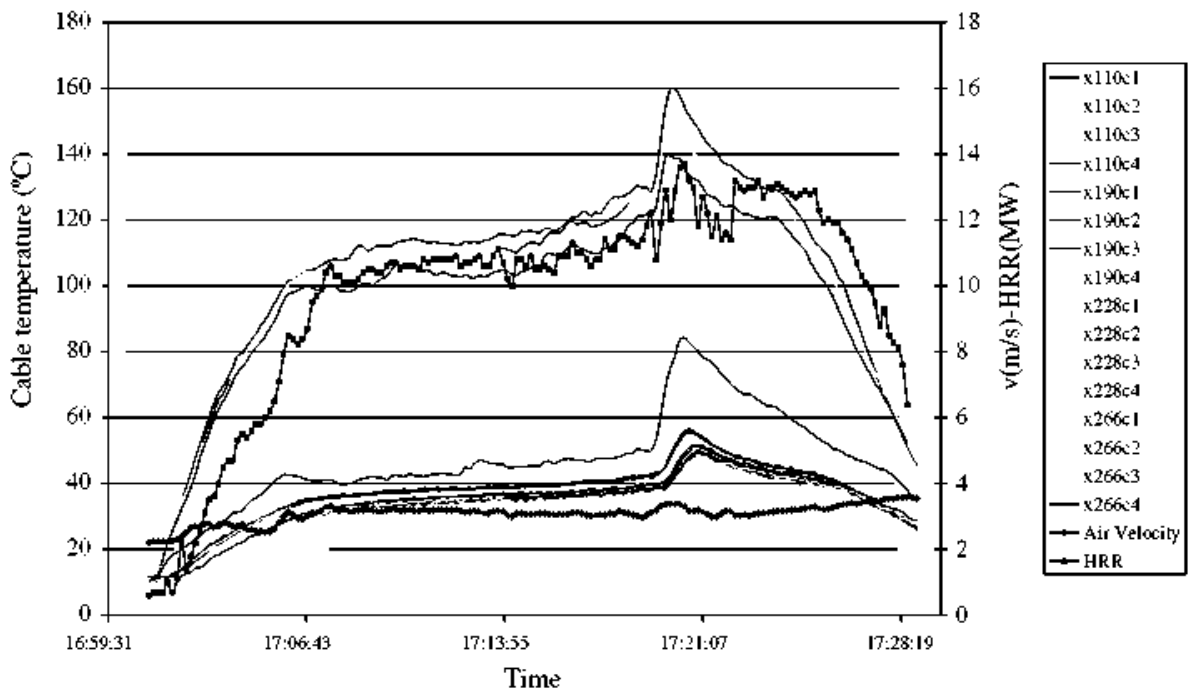

Fig. 14. Fiber cable temperatures and velocity measured and HRR estimated in case 6. 

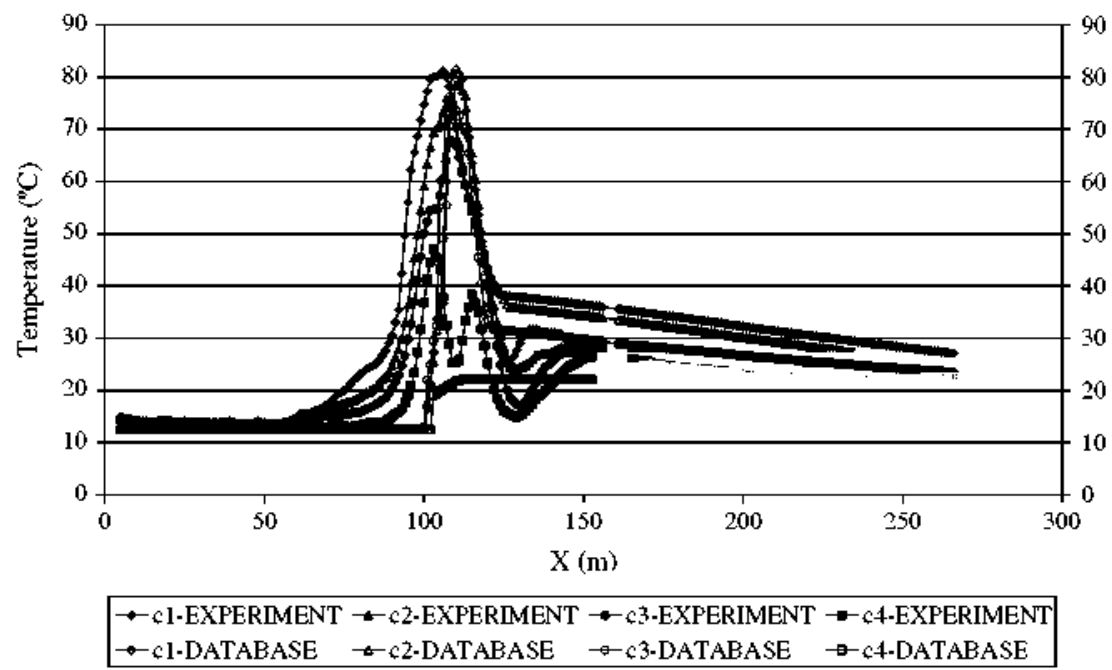

Fig. 15. Temperature distribution along the fiber cables. Comparison of experiments and results of the database. Case 5, instant 13:58:54.

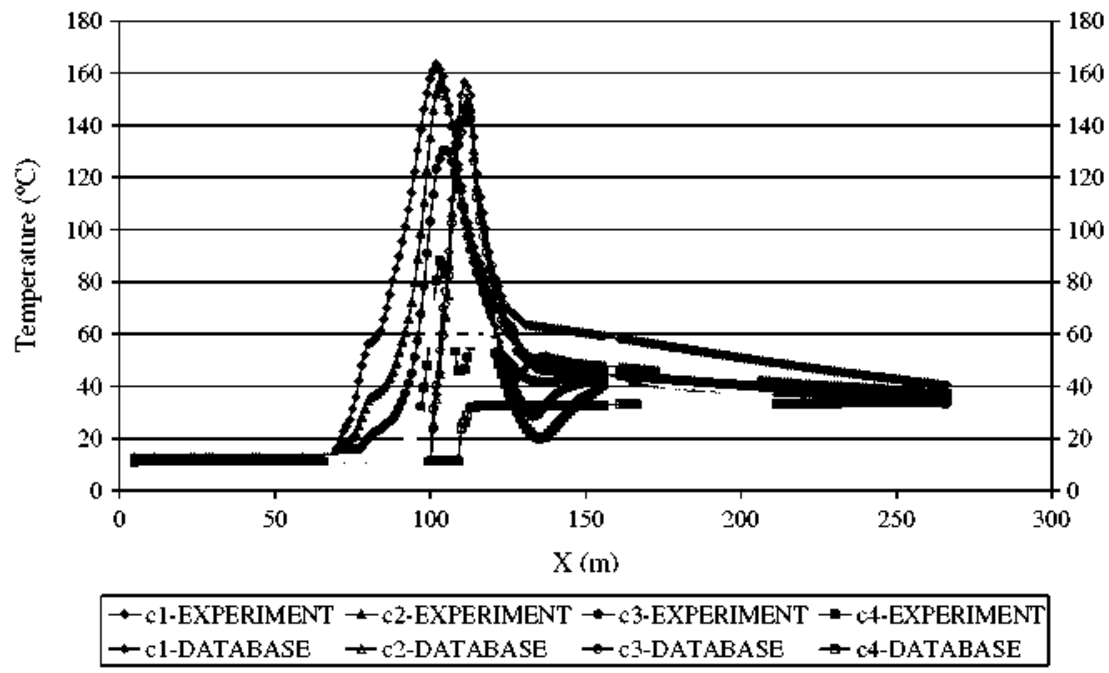

Fig. 16. Temperature distribution along the fiber cables. Comparison of experiments and results of the database. Case 6 , instant $17: 15: 43$.

the interpolated values of the UPMPTUNNEL database; gaps of data are due to the cross section change. The value of the HRR for the particular example of the case 5 , which appears in Fig. 15, is $5.25 \mathrm{MW}$, and the air speed is $2.87 \mathrm{~m} / \mathrm{s}$, corresponding to instant 13:58:54 of the fire, see Fig. 13. For the particular example of case 6 , appearing in Fig. 16, the values of the HRR and air velocity are $10.40 \mathrm{MW}$ and $3.05 \mathrm{~m} / \mathrm{s}$, respectively, and corresponds to instant 17:15:43 of the fire, see Fig. 14. As in Figs. 11 and 12, local estimated values have some discrepancies with the experiments but the mean values are next to measurements. Now, as the cables are not protected, the high temperatures near the fire have been measured and show good agreement with the calculated values. and this was not apparent for the flat ceiling cases. In general, the agreement between measured and calculated values of temperature is better now than in the previous cases with flat ceiling and gasoil fuel. Besides the heptane, another reason for the better agreement probably is that in this case the fiber cables are located $1 \mathrm{~m}$ away from the ceiling, far from the thermal layer near the wall, whereas in flat ceiling cases the cables were only $10 \mathrm{~cm}$ away from the wall. It can also be observed that there is an increase of the measured temperatures ahead of the fire that can not be reproduced by the UPMTUNNEL code.

\section{Conclusions}

The procedure and algorithm proposed for the determination of HRR of fires in tunnels provide suitable results if the database is sufficiently accurate. The instantaneous values of HRR are obtained in calculation times that are short enough to adapt the ventilation velocity to the power of the fire.

Some difficulties appear during the experiments, which could explain the discrepancies between the measured and estimated values of HRR. In cases 1-4, anomalous behaviours of the gasoil trays happened during flat ceiling tests. Therefore, cases 5 and 6 used heptane. Besides, in flat ceiling tests, the cable fibers close to the fire were covered due to the risk of damage and the measurements taken in the protected zone could not be used. Also the change of tunnel section is difficult to manage for the UMPTUNNEL model. The fibers too close to the vertical wall and the flat ceiling give not very representative measurements inside the tunnel, but it was necessary to put them there in order to not interfere with traffic in an actual road tunnel. Alternative positions should be investigated in future works.

In cases 1-4, with flat ceiling and gasoil as fuel, the air velocity changes very quickly, and its oscillations are drastically amplified 
when calculating HRR. But if the velocity changes smoothly, as in cases 5 and 6 with vault ceiling and heptane as fuel, the HRR evoJution follows well and smoothly the temperature evolution. Nevertheless, average values of the calculated HRR are generally in good agreement with the experimental data.

The validation procedure refers only to stationary cases and gives only the overall HRR. Experiments during which the instantaneous rate of burning of fuel can be determined will be of interest to compare with the predicted evolution of HRR. On the other hand, the calculation procedure should also be modified to include unsteady effects in a more accurate way than just taking into account the delay time between the fire location and the position where the corresponding temperature is measured.

\section{Acknowledgements}

We are very grateful to EUROESTUDIOS and Spanish Ministerio de Industria, Turismo y Comercio (PROFIT program) for providing the experimental data, financial support, and backing this research.

\section{References}

Alalt, T.T., Nilsen, A.R., 2009. Automatic fire detection in road traffic tunnels. Tunnelling and Underground Space Technology 24, 75-83.

A5TM E1354-03. Standard Test Method for Heat and Visible Smoke Release Rates for Materials and Products Using an Oxygen Consumption Calorimeter.

A5TM E2058-03. 5tandard Test Method for Measurements for Synthetic Polymer Material Flammability Using a Fire Propagation Apparatus (FPA).

Beaulieu, P., Dembsey, N., Alpert A. 2003. A new material flammability apparatus ands measurement techniques. In: Proceedings of SAMPE2003. Society for the Advancements of Materials and Process Engineering, Covina, CA.

Drysdale, D., 1999. An Introduction to Fire Dynamics. Wiley and Sons, Chichester,

Emmons, H., 1971. Fluid mechanics and combustion (plenary lecture). In: Proceedings of 13th lntemational Symposium on Combustion. pp. 1-18.

Galdo, M., Argüelles, K.M., Fernández, J.M., Ballesteros, R., Santolaria, C., 2008. Numerical 3D simulation of a longitudinal ventilation system: memorial Tunnel case. Tunnelling and Underground Space Technology 23. 539-551.

Hu, L.H., Huo, R., Peng, W. Chow, W.K. Yang, R.X., 2006. On the maximum smoke temperature under the ceiling in tunnel fires. Tunnelling and Underground Space Technology 21, 650-655.

Hu, L.H., Penga, W. Huoa, R, 2008. Critical wind velocity for arresting upwind gas and smoke dispersion induced by near-wall fire in a road tunnel. Joumal of Hazardous Materials 150 (1), 68-75.

Huggett, C., 1980 . Estimation of the rate of heat release by means of oxygen consumption. J. Fire Flammability 12, 61-65.

Hwang. C.C., Edwards, J.C., 2005. The critical ventilation velocity in tunnel fires - a computer simulation. Fire Safety Joumal 40,213-244. lngason, H., 2006a. Design fires in tunnels. Safe \& reliable tunnels, innovative european achievements. In: Second Intemational Symposium, lausanne, 2006.

lngason, $H$., 2006b. Fire testing in road and railway tumnels. In: Apted, V. (Ed.) Flammability Testing of Materials Used in Construction Transport and Mining. Woodhead Publishing, pp. 231-274.

lngason, H., Lönnermark, A, 2005. Heat release rates from heavy goods vehicle trailer fires in tunnels. Fire Safety Joumal 40, 646-668.

Jain, 5., Kumar, 5., Kumar, S., Sharma, T.P., 2008. Numerical simulation of fire in a tunnel: comparative study of CFAST and CFX predictions. Tunnelling and Underground Space Technology 23, 160-170.

Janssens, M.L., 1991. Measuring rate of heat release by oxygen consumption. Fire Technology 27, 234-249.

Kunsch, J.P., 2002. Simple model for control of fire gases in a ventilated tunnel. Fire Safety Journal 37, 67-81.

Kurioka, H., Oka, Y., Satoh, H., Sugawa, S., 2003. Fire properties in near field of square fire source with longitudinal ventilation in tunnels. Fire Safety Journal $38,319-340$.

leitner, A., 2001. The fire catastrophe in the Tauern tunnel: experience and conclusions for the Austrian guidelines. Tunnelling and Underground Space Technology 16,217-223.

Migoya, E. 2003. Modelo Zonal para la Simulación del Movimiento de Humos y Gases Calientes en Incendios: Aplicación a Túneles de Carretera. PhD Thesis, Universidad Politécnica de Madrid (in Spanish).

Migoya, E., Crespo, A., García, J., Hernández, J., 2009. A simplified model of fires in road tunnels. Comparison with three-dimensional models and full-scale measurements. Tunnelling and Underground Space Technology Incorporating Trenchless Technology Research Joumal 24, 37-52.

Oka, Y. Atkinson, G.T., 1995. Control of smoke flow in tunnel fires. Fires Safety Journal 25, 303-322.

Parker, W., 1982. Calculations of the heat release rate by oxygen consumption for various applications. NBS Report NBSIR 81, 2427.

PIARC. Fire and Smoke Control in Road Tunnels. PIARC Committee on Road Tunnels (C5), Paris, 1999.

Quintiere, J.G., 1998. Progress in fire science. In: Proceedings, Third Asia-Oceania Symposium on Fire Science and Technology, Singapore, pp. 3-14.

Roh, J.5., Ryou, H.S., Kim, D.H., Jung. W.S., Jang. Y.J., 2007. Critical velocity and burning rate in pool fire during longitudinal ventilation. Tunnelling and Underground Space Technology 22, 262-271.

Servert. J. Crespo, A., Hernández, J., 1997, A one-dimensional model of a turbulent jet diffusion flame in an ambient atmospheric flow, derived from a three-dimensional model. Combustion science and Technology 124, 83114.

Tieszen, S.R., 2001. On the fluid mechanics of fires. Annual Reviews Fluid Mechanics 33. 67-92.

Vuilleumier, F., Weatherill, A., Crausaz, B., 2002. Safety aspects of railway and road tunnel: example of the lötschberg lailway tunnel and Mont-Blanc road tunnel Tunnelling and Underground Space Teclmology 17, 153-158.

Woodburn, P.J., Britter, RE., 1996a. CFD simulations of a tunnel fire-part l. Fire Safety Journal 26, 35-62.

Woodburn, P.J., Britter, R.E., 1996b. CFD simulations of a tunnel fire-part ll. Fire Safety Journal 26, 63-90.

Wu. Y., Bakar, M.Z.A., 2000. Control of smoke flow in tunnel fires using longitudinal ventilation systems-a study of the critical velocity. Fire Safety Joumal 35, 363390.

Zukoski, Z.Z., 1995. Properties of fire plumes. In: Cox, G. (Ed.), Combustion Fundamentals of Fire. Academic Press, London, pp. 101-220. 